\title{
Experimental and theoretical behavior of cementitious plates containing ethylene vinyl acetate reinforced with glass woven fabric under impact load
}

\author{
Ali Dogan ${ }^{1}$, Nurullah Karaca ${ }^{1, *}$ \\ ${ }^{1}$ Department of Civil Engineering, Iskenderun Technical University, Iskenderun, Hatay, Turkey
}

\begin{abstract}
The paper is an analysis of the experimental and theoretical behavior of cementitious plate containing waste ethylene vinyl acetate (EVA) with and without reinforcement with glass fiber woven fabric (GFRP) under low-velocity impact load effect. Cementitious plates of $150 \mathrm{~mm} \times 150 \mathrm{~mm}$ size and three different thicknesses $(15 \mathrm{~mm}, 30 \mathrm{~mm}, 50 \mathrm{~mm})$ are produced by replacing the cement mixture aggregate with EVA at $0 \%, 18 \%, 32 \%, 45 \%$, and $56 \%$ by volume of aggregate. Then, the cementitious plates are coated with GFRP using vacuum infusion method. The effect of EVA and GRFP coatings on the dynamic impact behavior of cementitious plates is investigated by applying a low-velocity impact test on the produced cementitious plates with an impactor of $18 \mathrm{~mm}$ diameter, $10.50 \mathrm{~kg}$ weight, and $500 \mathrm{~mm}$ height. The data obtained from the experimental results are analyzed based on the mass-plate theory, lightweight (LWC) and normal weight (NWC) concrete, and the consistency of the theoretical results with the experimental results is compared. It has been determined that the use of NWC is more suitable for cementitious plates with an EVA replacement rate in the range of 0-32\%, while the use of LWC offers more optimum results if the EVA ratio is in the range of 32-56\%. Especially when the EVA displacement exceeds $32 \%$, it causes excessive void formation in the structure, resulting in a reduction in the dynamic impact loads of cementitious plates. GFRP coating with vacuum infusion method is not recommended for cementitious plate structures when the EVA replacement rate exceeds $32 \%$ by volume of aggregate.
\end{abstract}

Keywords: cementitious plates, ethylene vinyl acetate, drop weight impact test, vacuum infusion method, peak impact force

\section{Introduction}

Today, concrete is one of the most used building materials, with high strength, durability, longevity, and resilience [1]. In recent years, various unexpected structural collapses have occurred in reinforced concrete structures. Various overload conditions such as impacts, explosions, and earthquakes often cause structural damage or even collapse in concrete structures. In order to reduce such damages, studies on the structural design of concrete structures to withstand the impact load have increased day by day. Kennedy [2] reviewed the various empirical procedures used to determine penetration depth, perforation thickness, and scabbing thickness for concrete targets subjected to "hard" missile impact. It concluded that for projectile deformation to have a significant effect on perforation and scabbing thicknesses, missile deformation

\footnotetext{
* E-mail: nurullah.karaca@ iste.edu.tr
}

must be at least $40 \%$ of the calculated penetration depth for an undeformed missile. Adhikardy et al., [3] along with interpreting the results of the authors' previous test data, examined the transformation of the failure mode from bending failure under static loading to shear failure under impact load, and highlighted several issues regarding the impact response of beams. Yoo and Banthia [4] have made a review study on the impact strength of fiberreinforced concrete. They suggested combinations of fiber types to increase impact resistance. For this purpose, it is of great importance to develop concrete structural elements that will provide better resistance against overload conditions and to examine the dynamic impact behaviors of these structures.

In concrete production, sand and gravel (natural aggregate) sources or building materials such as polymers, ceramics, or waste materials obtained from them (synthetic aggregate) are used. Senthil 
Vadivel et al. [5] investigated the behavior of plain cement concrete and waste tire rubber aggregate concrete for impact loads under the effect of a steel ball drop weight. They stated that waste tire rubber aggregate, in which both fine and coarse aggregates are replaced by $6 \%$ rubber aggregates, significantly improves the impact resistance and ductility properties of concrete. Alwesabi et al. [6] investigated the effect of hybridization of polypropylene fiber and steel fiber on the fracture properties of plain and rubberized concrete (derived from waste tire) to determine the optimized blend ratio of fibers. They reported that concrete compressive and tensile strengths decrease due to crumb rubber change, but increase with hybrid $(0.1 \%$ polypropylene, $0.9 \%$ steel) fiber mixture. Ismail and AlHashmi [7] investigated the use of waste plastic $(0 \%, 10 \%, 15 \%$, and $20 \%$ ratio) instead of sand in concrete production. They said that by adding waste plastics to concrete mixes, the propagation of microcracks is stopped. Factors such as limited natural resources, damage to the environment during the extraction of natural aggregates, and higher cost of natural aggregates have led to the widespread use of synthetic aggregates. In this context, the use of recycled concrete aggregates as a complete or partial replacement for natural aggregates is of great importance in terms of sustainability, economy, and environmental impact. Makul et al. [8] investigated the development and capacity of practical applications of recycled aggregate concrete in Southeast Asia. They said that much needs to be learned about the activities and operations of construction and building waste to be effective towards the development of sustainable, durable, cost-effective, green concrete using recycled aggregates. Also, Makul et al. [9] presented a critical review of recycled concrete aggregates for the production of high-performance concrete structures. They reported that, depending on the source and type of recycled aggregate, it has a possible use in the production of high-performance structural concrete and can be used safely. Ethylene vinyl acetate (EVA) is one of the important synthetic polymers. EVA is a copolymer material; it is a waste material that cannot be reprocessed due to its chemical properties, occupies a significant volume due to its low density, and is difficult to dispose of in landfills, but has fire retardant properties, provides flexibility and sound insulation, and can be used as a substitute material in composite structures due to its low cost [10-13].

Based on a perusal of the literature, it can be inferred that when EVA is used in the concrete mixture, it increases the ductility and sound absorption capacity of the concrete. Lima et al. [14] investigated the effect of using two types of recycled aggregates from demolition and EVA waste as a substitute for natural coarse aggregates on the density, compressive strength, tensile splitting strength, and flexural behavior of recycled concrete. They reported that it is possible to use EVA and demolition waste to produce lightweight concrete (LWC) with semi-structural properties. Zuchetto et al. [15] investigated a cementitious flooring material used in floating floor systems made from recycled polymer EVA. The proposed material exhibits satisfactory acoustic properties and low mass per unit area compared to conventionally used materials and has great potential for use as the floating flooring material. In addition, it is observed that alternative application areas for the use of waste material EVA have been studied [12]. However, there are still debates on the effectiveness of the use of recycled EVA granules in concrete production, due to the decrease in especially mechanical properties and strength $[14,15]$.

Recently, there has been great interest in the impact behavior and engineering properties of fiber-reinforced concretes. This is because fiberreinforced concrete behaves more ductile than conventional concrete [4, 6]. Various fibers such as metallic, glass, and synthetic polymer fibers are used as reinforcement elements in concrete structures. Magbool and Zeyad [16] studied the effect of the inclusion of volcanic pumice powder and various steel fibers on the fracture toughness parameters of self-compacting concrete. They reported that the steel fiber reduces the fresh concrete properties of self-compacting concrete. Balcikanli Bankir and Sevim [17], interactional effects of four different fiber types (steel, glass, synthetic and polypropylene), fly ash replacement ratio with cement, electric arc furnace slag replacement ra- 
tio with natural aggregate and binder dosage on the mechanical properties of hybrid fiber concrete have been studied. Analysis of variance was performed using experimental test results and regression models were obtained. They have been suggested that the optimum combination, optimizing the dependent variables.

Glass/carbon-fiber-reinforced polymer (GFRP/CFRP) have found more widespread use in engineering applications compared to other reinforcement elements due to their high strength/weight ratio and high corrosion resistance. Similarly, fibers used in cementitious matrices increase the properties of concrete such as tensile and flexural strength, impact resistance, and fracture energy. Anil et al. [18] investigated the behavior of reinforced concrete slabs under impact load with four different support arrangements for both fixed and articulated support conditions. They also created a finite element model. They reported that the type of support and their placement had a significant effect on the behavior of reinforced concrete slabs when subjected to impact loads. They further reported that the finite element analysis results would be useful in terms of providing an idea about the impact capacity and behavior of reinforced concrete slabs at the design stage. Mubin et al. [19] reviewed previous research on experimental and numerical studies on the impact behavior of fiber-reinforced polymer strips reinforced concrete slabs with various strip arrangements. They reported that the experimental results significantly improved the diagonal two-way arrangement of the fiber-reinforced polymer strips externally bonded on the bottom surface of the reinforced concrete slabs and the impact strength of the applied four hinge supports. Composite structures are formed by adding fibers to the structure by methods such as hand lay-up, filament winding, compressing molding, spray-up, or vacuum infusion. Although the vacuum infusion method [20] is a more costly production method than other methods, it is preferred in composite structures [21] due to its advantages such as homogeneous distribution of reinforcement elements in the structures, lower void ratio, repeatability, and higher mechanical properties [22].
However, a study using the vacuum infusion method in concrete structures has not been found in the open literature. Thus, in this study, GFRP coating is applied using the vacuum infusion method in order to improve the impact resistance of cementitious plates containing EVA. Then, the forcetime graphs are obtained by exposing the samples to the low-velocity impact test, and the effect of EVA contribution and CRFP coating is examined by calculating the peak impact forces with the help of the mass-plate theory.

\section{Experimental study}

The experimental study involves production of cementitious plates in four different situations, namely plain cementitious plates, cementitious plates coated with GFRP, cementitious plates containing different proportions of EVA $(18 \%, 32 \%$, $45 \%$, and $56 \%$ by volume of aggregate), and cementitious plates coated with GFRP containing EVA $(18 \%, 32 \%, 45 \%$, and $56 \%$ by volume of aggregate).

The samples are produced in the form of plates and beams, the dimensions of the plates are $150 \mathrm{~mm} \times 150 \mathrm{~mm}$ in side length and 15-30$50 \mathrm{~mm}$ in thickness, and the beams are produced in the size of $160 \mathrm{~mm} \times 40 \mathrm{~mm} \times 40 \mathrm{~mm}$. The nomenclature of the samples is given in Table 1 .

Table 1. Nomenclature of the produced cementitious plate samples

\begin{tabular}{lll}
\hline $\begin{array}{l}\text { Plate } \\
\text { designation }\end{array}$ & $\begin{array}{l}\text { Replacement ratio of } \\
\text { EVA (by volume) }\end{array}$ & Coating GFRP \\
\hline \hline PC & 0 & - \\
L18 & 18 & - \\
L32 & 32 & - \\
L45 & 45 & - \\
L56 & 56 & - \\
CPC & 0 & Coated \\
CL18 & 18 & Coated \\
CL32 & 32 & Coated \\
CL45 & 45 & Coated \\
CL56 & 56 & Coated \\
\hline
\end{tabular}

EVA, ethylene vinyl acetate; GFRP, glass fiber woven fabric 


\subsection{Materials}

\subsubsection{Cement}

In this study, the aim is normal strength concrete design. Standard CEM I 42.5 R Portland cement is used in the production of samples. Master Glenium SKY 608 coded from the BASF company material is used as a superplasticizer concrete admixture. Table 2 shows the properties of cement and superplasticizer used.

\subsubsection{Aggregate}

In the study, dolomite-limestone origin aggregate, obtained from quarries in the Iskenderun region of Turkey, is used. Maximum grain size of the aggregate is $4 \mathrm{~mm}$.

EVA can be found in two forms, solid and liquid. In the study, solid form EVA material obtained from the waste products of materials used as insoles and insoles in the footwear industry is used. EVA is produced waste from shoe soles in Alkan Sole Factory in Antakya Organized Industrial Zone. To ensure that the granulometry of the EVA material is in the desired dimensions, sieving is performed on the materials. Then, EVA between $2 \mathrm{~mm}$ and $4 \mathrm{~mm}$ grain size is added to the mixture as a substitute in place of aggregate. The properties of aggregates and replacement EVA are shown in Table 2.

Table 2. Properties of the materials that make up cementitious plates

\begin{tabular}{|c|c|c|}
\hline Materials & Properties & Type \\
\hline Cement & $\begin{array}{l}\text { Density: } \\
3.15\left(\mathrm{~g} / \mathrm{cm}^{3}\right)\end{array}$ & $\begin{array}{l}\text { Type I blane } \\
\text { fineness: } \\
3,250\left(\mathrm{~kg} / \mathrm{m}^{2}\right)\end{array}$ \\
\hline Aggregates & $\begin{array}{l}\text { Density: } \\
2.6\left(\mathrm{~g} / \mathrm{cm}^{3}\right)\end{array}$ & Sand $4 \mathrm{~mm}$ \\
\hline EVA & $\begin{array}{l}\text { Density: } \\
0.55\left(\mathrm{~g} / \mathrm{cm}^{3}\right)\end{array}$ & $2-4 \mathrm{~mm}$ \\
\hline Water & Potable & \\
\hline Superplasticizer & $\begin{array}{l}\text { Specific } \\
\text { gravity } \\
\left(20^{\circ} \mathrm{C}\right) \text { : } \\
1.069-1.109 \\
(\mathrm{~kg} / \mathrm{l})\end{array}$ & $\begin{array}{l}\text { Polycarboxylic } \\
\text { ether based }\end{array}$ \\
\hline
\end{tabular}

EVA, ethylene vinyl acetate

\subsubsection{Glass fiber woven fabric}

Glass fiber woven fabric (GFRP) with a density of $600 \mathrm{~g} / \mathrm{m}^{2}$ and an orientation angle of $0 / 90$ is used as the coating material. The properties of glass fiber woven fabric are given in Table 3 (provided by the manufacturer).

Table 3. Properties of glass fiber woven fabric

\begin{tabular}{ll}
\hline Fiber type & Woven fabric $\left(\mathbf{g} / \mathbf{m}^{\mathbf{2}}\right)$ \\
\hline \hline Areal weight & $600 \mathrm{~g}( \pm 5 \%)$ \\
Style/Pattern & Biax $0-90-$ stitch \\
Tensile strength & $3,500(\mathrm{MPa})$ \\
Tensile modulus & $72(\mathrm{GPa})$ \\
\hline
\end{tabular}

\subsubsection{Resign epoxy}

Hexion brand MGS L160 coded epoxy resin and H160 coded hardener material is used as matrix material. The material is commercially available. Table 4 shows the material properties of epoxy resin and hardener (provided by the manufacturer).

Table 4. Properties of resin epoxy and resin hardener

\begin{tabular}{lll}
\hline & L160 & H160 \\
\hline \hline $\begin{array}{l}\text { Density }\left(\mathrm{g} / \mathrm{cm}^{3}\right) \\
\text { Viscosity (MPa) }\end{array}$ & $\begin{array}{l}1.13-1.17 \\
700-900\end{array}$ & $\begin{array}{l}0.96-1.00 \\
10-50\end{array}$ \\
$\begin{array}{l}\text { Epoxy equivalent } \\
\text { (g/equivalent) }\end{array}$ & $166-182$ & \\
$\begin{array}{l}\text { Epoxy value } \\
\text { (value/100 g) }\end{array}$ & $0.55-0.60$ & \\
$\begin{array}{l}\text { Refractor } \\
\text { index }\end{array}$ & $1.5480-$ & $1.5200-$ \\
$\begin{array}{l}\text { Measurement } \\
\text { conditions }\end{array}$ & 1.5530 & 1.5210 \\
$\begin{array}{l}\text { Flexural strength } \\
\text { (MPa) }\end{array}$ & $25^{\circ} \mathrm{C}$ & $25^{\circ} \mathrm{C}$ \\
$\begin{array}{l}\text { Modulus of elasticity } \\
\text { (GPa) }\end{array}$ & $3.2-3.5$ & \\
$\begin{array}{l}\text { Tensile strength } \\
\text { (MPa) }\end{array}$ & $70-80$ & \\
$\begin{array}{l}\text { Elongation at break } \\
\text { (\%) }\end{array}$ & $5.0-6.5$ & \\
\hline
\end{tabular}


Table 5. Concrete mix design

\begin{tabular}{|l|l|l|l|l|l|}
\hline Sample & $\begin{array}{l}\text { Weight cement } \\
(\mathbf{k g})\end{array}$ & $\begin{array}{l}\text { Weight water } \\
(\mathbf{k g})\end{array}$ & $\begin{array}{l}\text { Weight plasticizer } \\
(\mathbf{k g})\end{array}$ & $\begin{array}{l}\text { Weight aggregate } \\
(\mathbf{k g})\end{array}$ & $\begin{array}{l}\text { Weight EVA } \\
(\mathbf{k g})\end{array}$ \\
\hline \hline PC & 507.28 & 253.64 & 2.54 & $1,521.83$ & 0 \\
L18 & 507.28 & 253.64 & 2.54 & $1,369.65$ & 61.46 \\
L32 & 507.28 & 253.64 & 2.54 & $1,217.47$ & 122.92 \\
L45 & 507.28 & 253.64 & 2.54 & $1,065.28$ & 184.38 \\
L56 & 507.28 & 253.64 & 2.54 & 913.10 & 245.83 \\
\hline
\end{tabular}

EVA, ethylene vinyl acetate

\subsection{Production of test samples}

\subsubsection{Molding of cementitious plates}

While the cementitious plate is being produced, the mixture is prepared in a 3:0.5:1 ratio [23] with sand-aggregate, water, and cement, respectively, as the constituents, and mixed with the help of a concrete mixer. To improve the workability and flowability of mortar in molds, a $0.5 \%$ superplasticizer is added during the mixing of the slurry. To allow the concrete mixture to penetrate deeply into the molds, the concrete mixture is rodding with the help of an iron rod. The produced samples are retained in the molds for $24 \mathrm{~h}$. The samples are taken out of the molds after $24 \mathrm{~h}$ and cured under weather conditions. The mixing amounts of the materials required for cementitious plates' production are given in Table 5.

\subsubsection{Fabrication of GFRP-cementitious plates with vacuum infusion}

In the production using the vacuum infusion method, glass fiber woven fabric with a density of $600 \mathrm{~g} / \mathrm{m}^{2}$ and a 00/900 angle orientation is used. Hexion brand MGS L160 epoxy and H160 coded hardener is used as matrix material. The process steps of the vacuum infusion method can be seen schematically in Figure 1. For the core region of the coated composite plate, cementitious plates are used. While producing hybrid composite plates, they are produced with two glass fiber layers at the bottom $\left(90^{\circ} / 0^{\circ} / 90^{\circ} / 0^{\circ}\right)$, a cementitious plate layer in the middle and two layers of glass fiber woven fabric at the top $\left(0^{\circ} / 90^{\circ} / 0^{\circ} / 90^{\circ}\right.$, Figure 1). The ratio $(\mathrm{f} / \mathrm{m})$ of fiber and matrix materials used for the produced hybrid composite samples is approximately

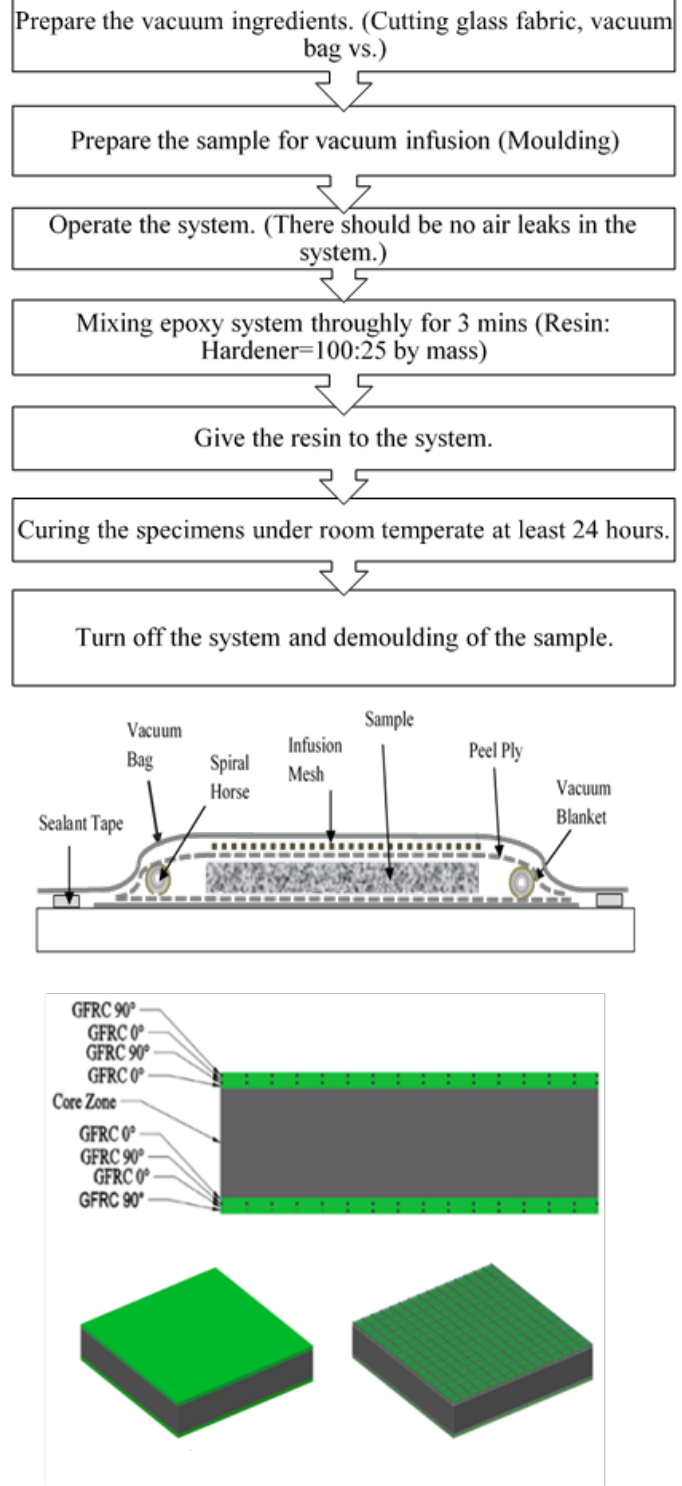

Fig. 1. Processes of vacuum infusion 
$60 \%$ by weight. For matrix materials, epoxy MGS L160 and hardener H160 are mixed in the mass ratio of 100:25. The curing is carried out at room temperature for $24 \mathrm{~h}$ under a pressure of $0.35 \mathrm{MPa}$.

\subsubsection{Compressive and drop weight impact test}

The compression test is applied to the produced cementitious beam samples with dimensions of $160 \mathrm{~mm} \times 40 \mathrm{~mm} \times 40 \mathrm{~mm}$, in accordance with the ASTM C349-02 [24] standard, on the 28th day (Figure 2A).

An INSTRON brand CEAST 9350 model impact test device is used for the low-velocity impact tests applied to the samples (Figure 2B). The samples are impacted with a hemispherical steel impactor tup of $18 \mathrm{~mm}$ diameter with a mass of $10.5 \mathrm{~kg}$. The plate samples are exposed to impact with the help of an object released from a height of $500 \mathrm{~mm}$. All experiments are conducted at room temperature and the type of support is a four-sided sliding bearing.

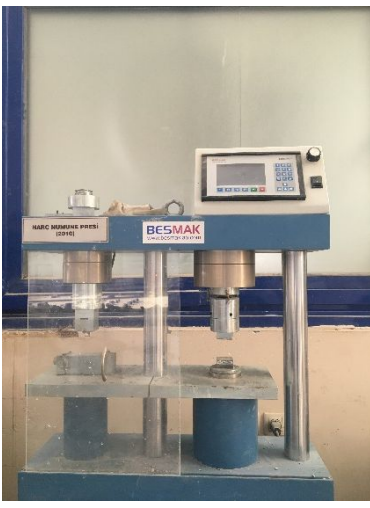

(A)

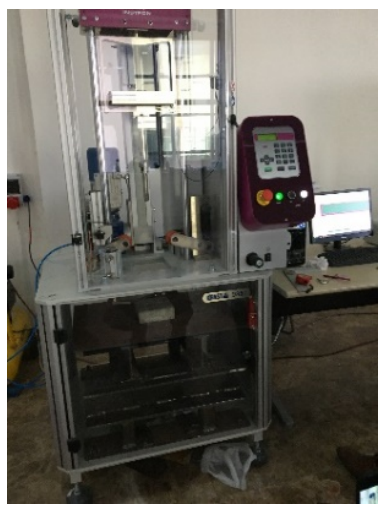

(B)
Fig. 2. Test machine (A) compressive strength (B) lowvelocity impact

\section{Results and discussion}

\subsection{Densities}

The workability decreased with the incorporation of EVA into cementitious slabs. Superplasticizer is added to restore workability. The results are in good agreement with those reported in a previ-

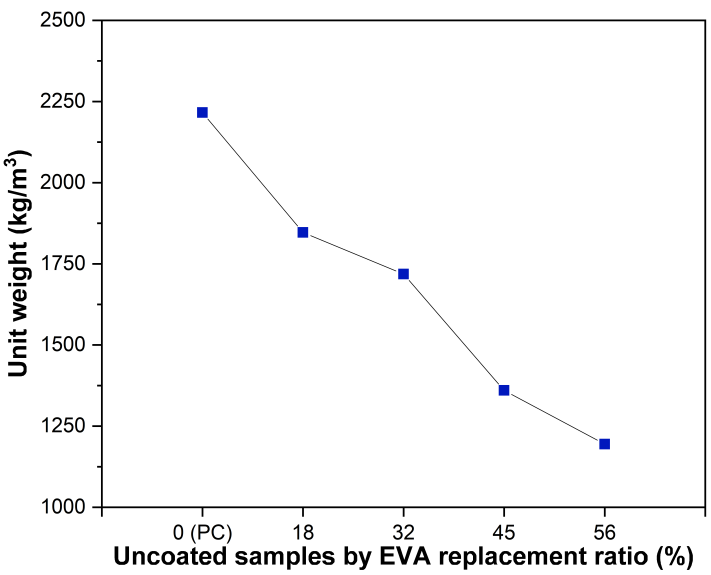

(A)

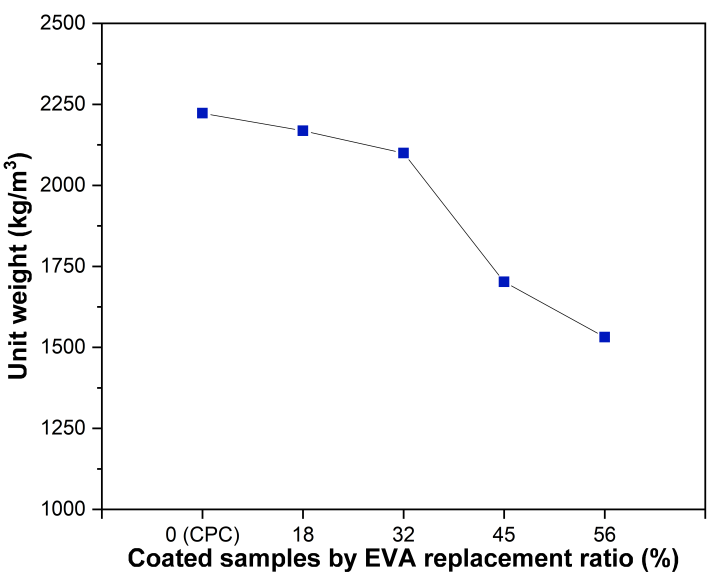

(B)

Fig. 3. Unit weight changes of cementitious samples depending on (A) EVA replacement ratio by volume (B) EVA replacement ratio by volume and GFRP coating process. EVA, ethylene vinyl acetate; GFRP, glass fiber woven fabric

ous study [15]. Figure 3 shows the unit weight values of the samples depending on the EVA replacement. As shown in Figure 3A, with the increase of EVA replacement, a decrease is determined in the unit weight values of the samples compared to the control concrete, and this decreased value is in the range of $17-46 \%$, which is consistent with the results of studies in the literature $[14,15]$. Lima et al. [14] stated that with EVA replacement in the range of $50 \%$, the unit weight values of concrete decreased in the range of $92 \%$, while Zuchetto et al. [15] determined a decrease of 5-63\% in concrete unit weight values with 0-100\% EVA replacement. 
The fact that the data obtained in our current study are close to those provided in Strong's study [20] but slightly different from those in Lima et al. [20] can be attributed to two reasons, namely the EVA replacement rate and the EVA particle size employed in the experiments conducted as part of these studies. The first of these, as seen in our study, caused excessive void formation in concrete structures when the EVA replacement exceeded $32 \%$. The other is that due to the smaller particle size, the EVA admixture is mixed more homogeneously in the concrete content while reducing the amount of space in the structure of the concrete and increasing the concrete unit weight value. On the other hand, there is a normal decrease in unit weights of GFRP-coated plate samples up to samples containing 32\% replacement EVA. (Figure 3B). The decrease in sample unit weight is more noticeable after the percentage of replacement EVA exceeds $32 \%$. This is because of the amount of gap between the EVA and cement matrix. On the other hand, it is determined that the GFRP coating exhibited a gradual decrease in the concrete unit weight values up to $32 \%$ replacement rate due to the increase in the EVA additive, while it showed a dramatic decrease after 32\% (Figure 3B). The reason for this is that epoxy can be absorbed in the range of $10-15 \%$ due to the reasonable level of void ratios in the concrete up to $32 \%$ EVA replacement ratio, while in cases the EVA replacement ratio exceeds $32 \%$, depending on the excessively increased amount of voids in the concrete structure, the epoxy absorption of the concrete may be increase its efficiency up to $30-40 \%$ range [25].

\subsection{Static test results}

Compressive strength values obtained from EVA-replaced and GFRP-coated samples after EVA replacement, which are subjected to the compressive strength test according to ASTM C349-02 [24] standard, are shown in Figure 4.

As seen in Figure 4A, it has been determined that the control cementitious sample provides higher compressive strength than the EVAreplaced samples, and this has been reported in many studies in the literature. Moreover, although it has been determined that there is an unexceptional decrease in the compressive strength values due to the increase of EVA replacement, it has also been determined that the compressive strength values show a dramatic decrease after 32\% EVA replacement, and the compressive strength value decreases to approximately $1 \mathrm{MPa}$ with 56\% EVA replacement. This is due to the fact that the density value $\left(0.55 \mathrm{~g} / \mathrm{cm}^{3}\right)$ of the EVA material is lower than that of the aggregate materials $\left(2.7 \mathrm{~g} / \mathrm{cm}^{3}\right)$ $[14,15]$.

The GFRP coating process increased the compressive strength values of both the control cementitious sample and all of the EVA-replaced samples (Figure 4B). This is a result of the mechanical properties of GFRP-added epoxy being superior to concrete [26]. As a matter of fact, in our study, the control cementitious sample exhibited a compressive strength value of $31.43 \mathrm{MPa}$, while the GFRPcoated sample exhibited a compressive strength value of $42.07 \mathrm{MPa}$. On the other hand, compressive strength values of EVA-replaced and GFRPcoated samples are lower than those of the control cementitious samples. However, the decrease in compressive strength of EVA-replaced and GFRPcoated samples is less than that of EVA-replaced samples. This shows that GFRP coating provides an improvement in compressive strength to a certain extent. As a matter of fact, after 32\% EVA replacement, the compressive strength value in the EVA-replaced samples without GFRP coating is found to be in the range of $0-1 \mathrm{MPa}$, while the compressive strength value in the samples that are GFRP-coated and contain more than $32 \%$ EVA is found to be in the range of 4-23 MPa. In particular, the 22.91 MPa pressure value detected in the 45\%EVA-substituted-and-GFRP-added sample is noteworthy. The increase in the compressive strength value obtained in the sample with more than $32 \%$ EVA substitute is a result of the filling of the voids in the structure with resin as a result of the cementitious samples shown in Figure $4 \mathrm{C}$ absorbing more resin. 


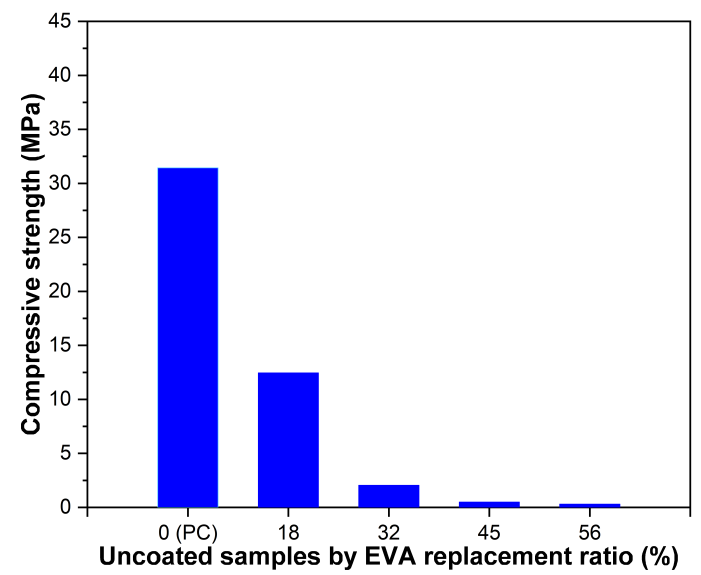

(A)

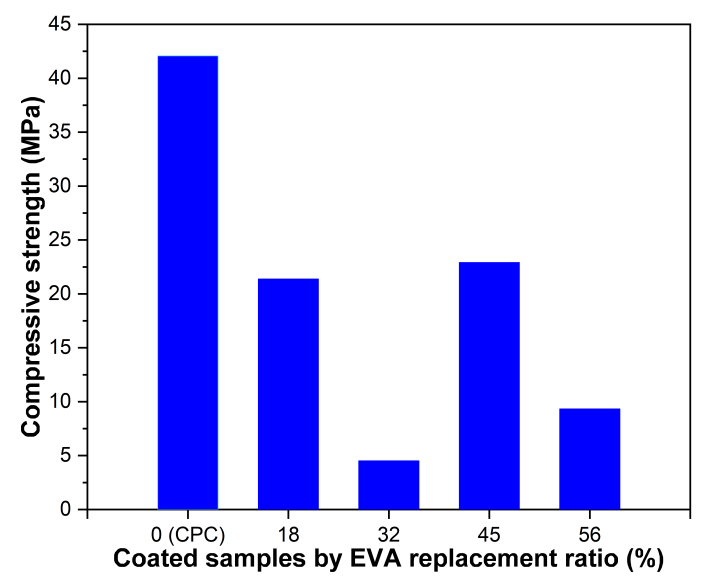

(B)

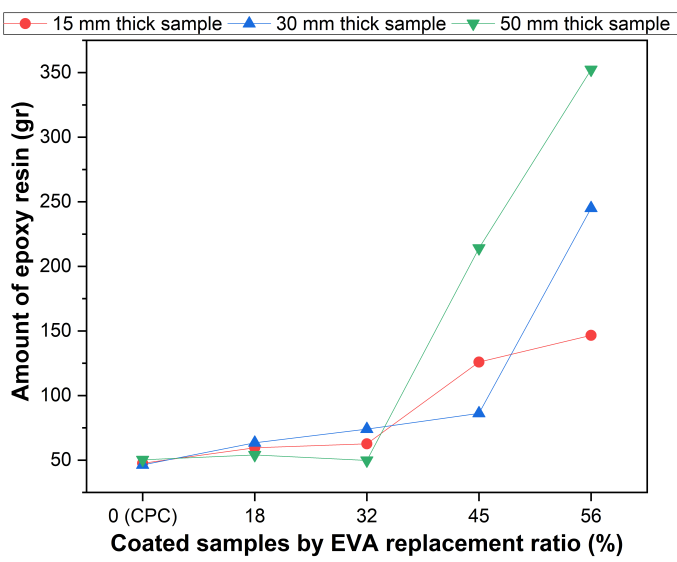

(C)

Fig. 4. Average maximum compressive stress (A) uncoated samples $(\mathbf{B})$ coated samples $(\mathbf{C})$ amount of resin epoxy for samples with various thicknesses. EVA, ethylene vinyl acetate

\subsection{Dynamic test results}

The maximum first peak load values of the samples can be seen in Figure 5. It is clearly seen from Figure 5 that the maximum load decreases with an increasing amount of EVA, and the maximum load increases as the sample thickness increases [19]. It can be also said that samples coated with GFRP have a higher load-carrying capacity than uncoated samples. As the amount of replacement EVA in concrete increases, the peak impact force value decreases. However, when coated with GFRP material, the peak impact force values increase significantly (Figure 5). This is because the EVA material creates voids in the concrete content, while reducing the mechanical properties; on the other hand, during the GFRP coating process, the voids on the surface of the cementitious structures can be filled with resin with higher mechanical properties than cement. The reason for the limited increase in these mechanical properties is that the resin penetrates only the surface of the concrete and cannot reach the cavities in the interior.

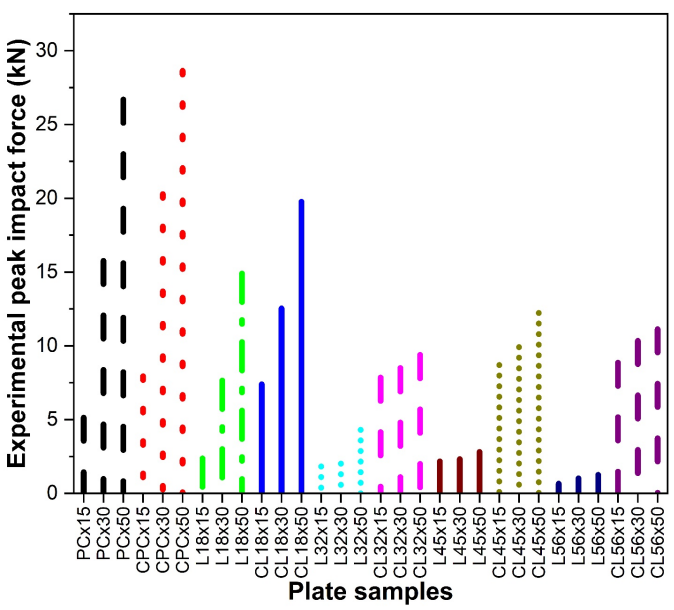

Fig. 5. Dynamic test results: maximum load for uncoated and coated plate samples

In Figure $6 \mathrm{~A}-\mathrm{C}$, force-time curves under the impact force of samples containing various proportions of EVA are shown. It is observed that the peak impact force values decrease as the amount of replacement EVA increases in the plates containing PC and replacement EVA. Therefore, PC samples have higher compressive strength than sam- 


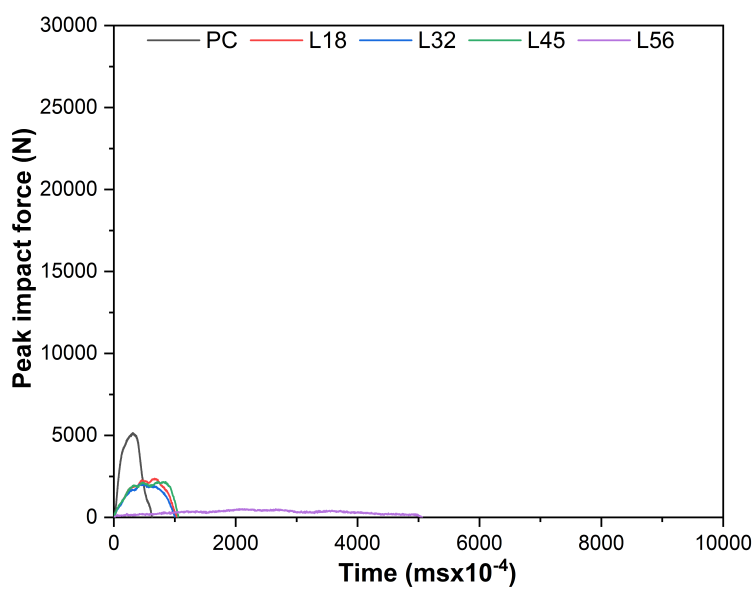

(A)

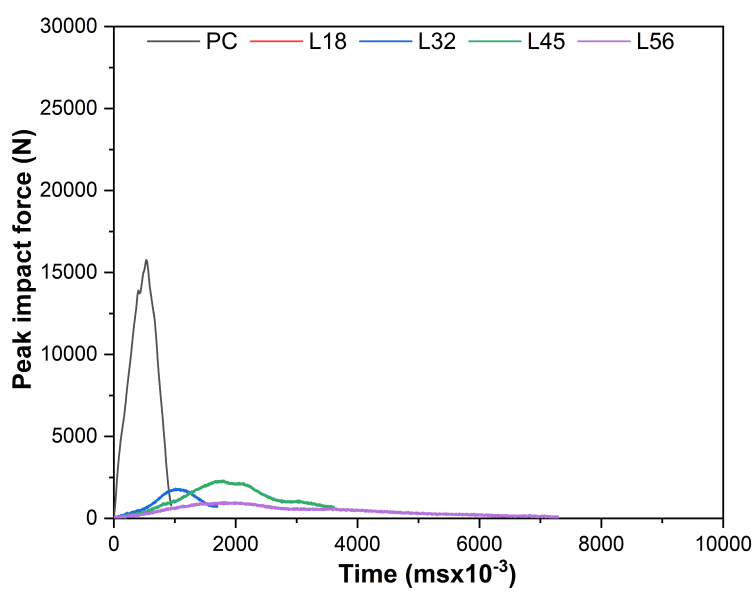

(B)

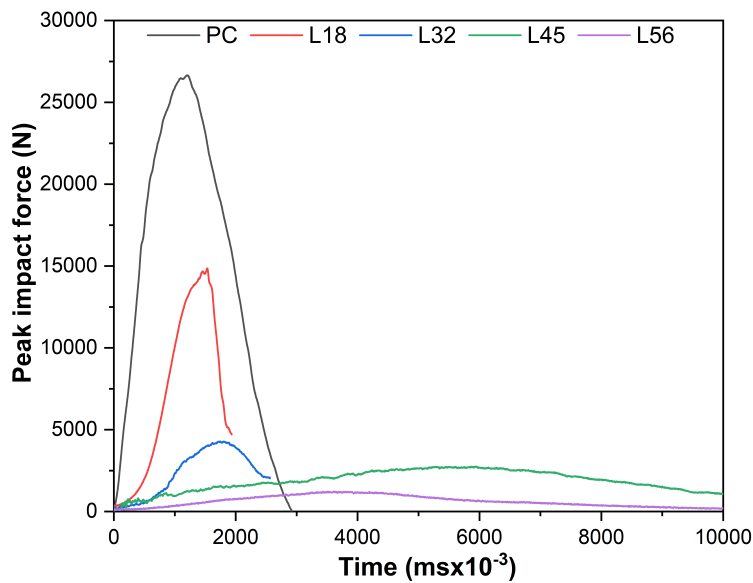

(C)

Fig. 6. Force-time curves for PC, L18, L32, L45, and L56 samples (A) $15 \mathrm{~mm}$ (B) $30 \mathrm{~mm}$ (C) $50 \mathrm{~mm}$ thickness

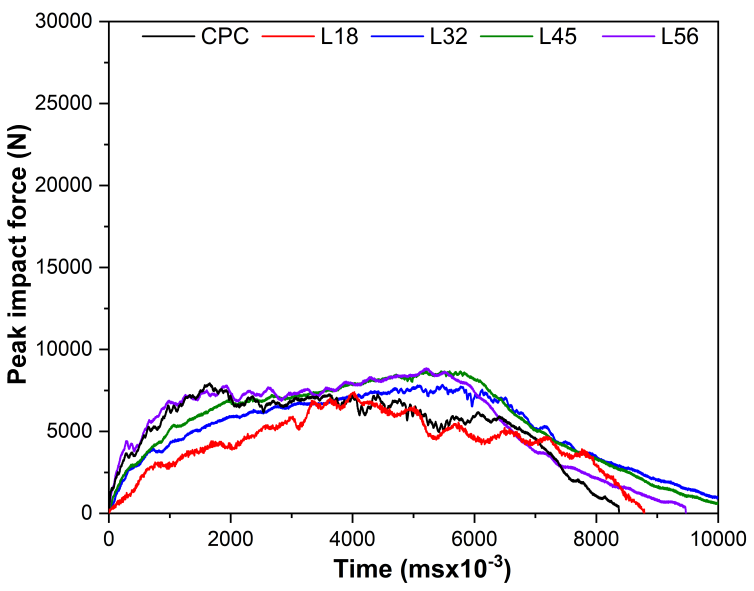

(A)

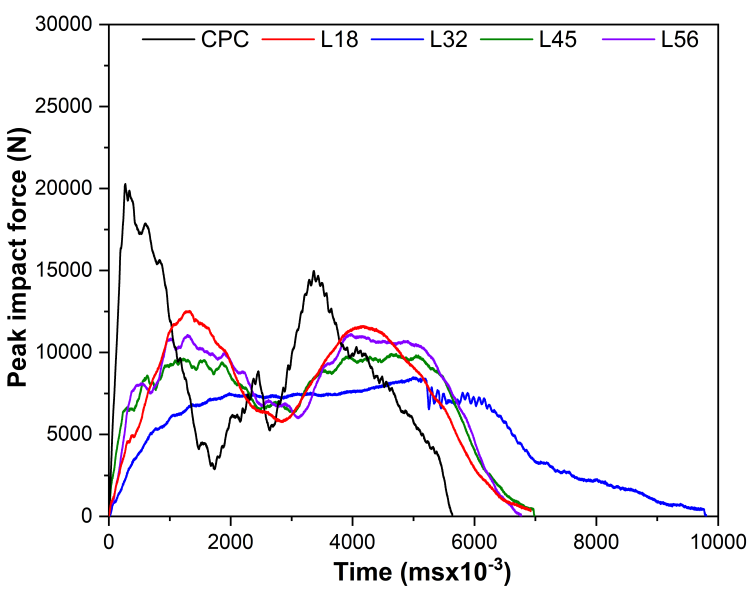

(B)

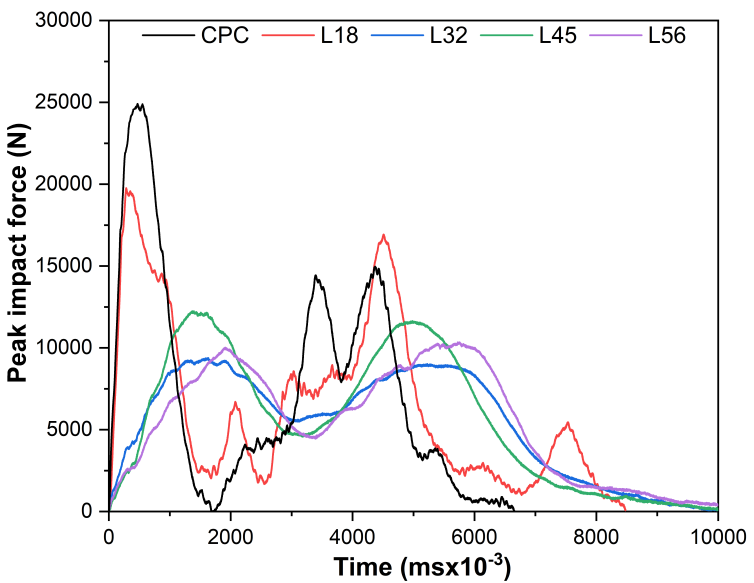

(C)

Fig. 7. Force-time curves for CPC, CL18, CL32, CL45, and CL56 samples (A) $15 \mathrm{~mm}$ (B) $30 \mathrm{~mm}$ (C) $50 \mathrm{~mm}$ thickness 
ples containing replacement EVA. As the amount of EVA increases, its compressive strength and impact strength decrease. In addition, the time to peak in the force-time figure of the samples containing $56 \%$ EVA increases.

Depending on the increase of EVA replacement, a decrease in the peak impact force values occurred (Figure 6). In addition, as the thickness of the samples increases, the peak impact force values and the peak impact time values also increase (Figure 6AC). This indicates that the cementitious samples exhibit a more ductile behavior with the increase in thickness in the samples.

In Figure $7 \mathrm{~A}-\mathrm{C}$, the force-time curves of the GFRP-coated samples under the impact force are seen. As can be seen from an examination of Figure $7 \mathrm{~A}-\mathrm{C}$, as the amount of EVA increases, the peak impact force values decrease. The peak impact force also shifts to the right along with the time axis. In addition, the peak impact forces obtained for the different EVA ratios of the GFRPcoated samples are closer to each other than in the uncoated case. While the samples containing EVA are coated by the vacuum infusion method, it is thought that the peak impact force increases due to resin filling of the pores in the EVA concrete. As the amount of EVA increases, the amount of pores increases. Accordingly, the amount of epoxy taken into the gaps also increases. As the amount of EVA increases, the ductility of the plate sample also increases. Therefore, it is thought that the time of the peak impact force formation is shifted to the right in samples containing EVA.

Considering the force-time curves of the GFRPcoated samples (Figure 7A-C) compared to the uncoated samples (Figure 6A-C), an increase is observed in the peak impact values. In addition, it can be seen that, unlike the uncoated samples (Figure $6 \mathrm{~A}-\mathrm{C}$ ), double peak impact values are measured in the force-time curves of the GFRP-coated samples. The increase in the impact peak values is a result of the effect of the superior mechanical properties of GFRP in improving the mechanical properties of cementitious samples [26]. The fact that the samples showed a double peak value (Figure 7A-C) instead of a single peak value (Figure $6 \mathrm{~A}-\mathrm{C}$ ) is a result of the fact that the GFRP- added epoxy and the cement core structure have different impact resistance. Double peak pulse (the hill-pit-hill formation) value can be seen in $\mathrm{Mu}-$ bin et al. [19]. It is stated that it is also observed in cementitious samples produced by hand lay-up in Figure $7 \mathrm{~A}-\mathrm{C}$, and it is stated that the double peak impact value increased the damping time. On the other hand, when the thickness change force-time curves of the EVA substituted GFRP-coated samples are examined (Figure $7 \mathrm{~A}-\mathrm{C}$ ), it is seen that the peak impact force values decrease with the increase in the EVA replacement ratio as in the uncoated EVA samples and increase with the increase in the thickness values of the samples. It is seen that the peak impact force values are shifted to the right in the GFRP-coated samples, as in the samples without GFRP coating. This indicates that the addition of the EVA replacement to the samples increases the ductility and is unaffected by the GFRP coating process. Moreover, an increase in thickness resulted in a more evident hill-pit-hill formation. This might be attributed to the fact that under axial impact, the applied force is mainly taken by the cementitious part of the sample [27].

\subsection{Damage views after impact test}

The damage appearances of the samples subjected to the low-velocity impact test under $10.5 \mathrm{~kg}$ impact load are shown in Figure 8A-I. As seen in Figure 8, all uncoated samples have failed after the applied load of $10.5 \mathrm{~kg}$, except the PC sample with $50 \mathrm{~mm}$ thickness. When the failure mechanisms are examined (Figure 8A, B), it can be seen that the failure mechanism occurred as thin linear fractures in the samples without EVA replacement, while it can be seen that the failure mechanism occurred in the form of more prominent thick linear fractures and local dispersions (surrounding impact zone) in the samples with EVA replaced (Figure 8C-F).

On the other hand, it is seen that linear fracture did not occur in all of the GFRP-coated samples. The damage of the samples is limited to only the impact zone area, and this type of damage is reported by Cheng et al., [28] who named it "whitening". The authors defined whitening as the damage of only the GFRP coating in the structure of the 


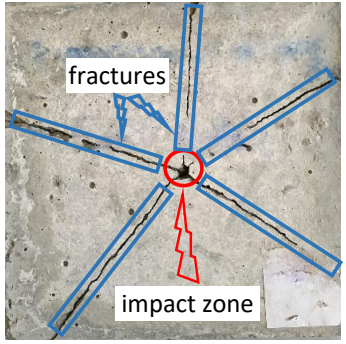

(A)

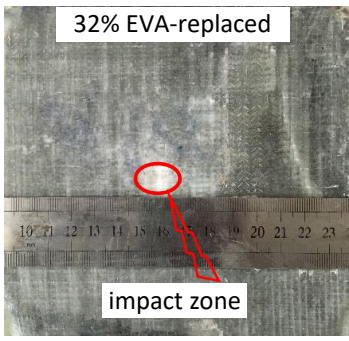

(D)

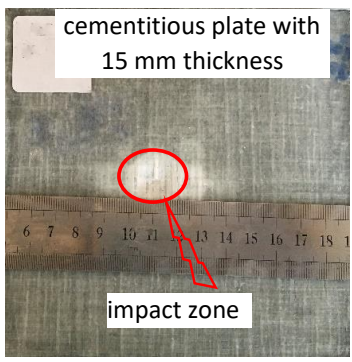

(G)

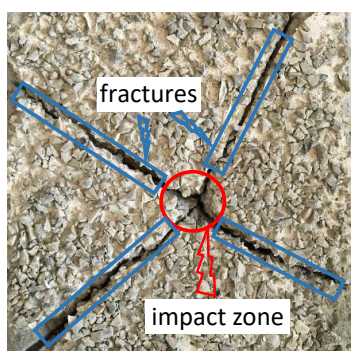

(B)

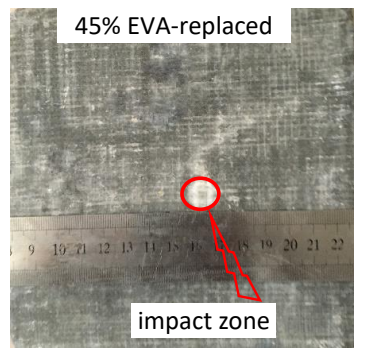

(E)

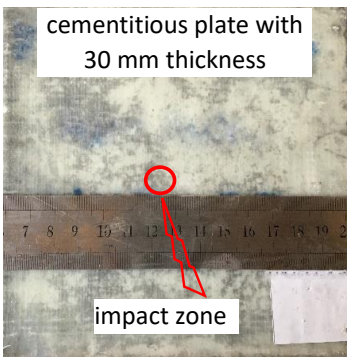

(H)

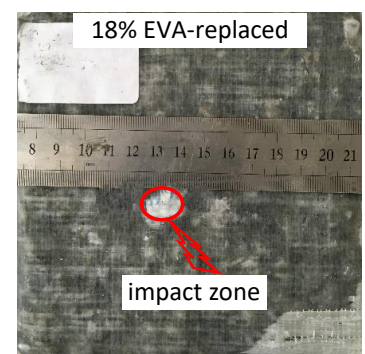

(C)

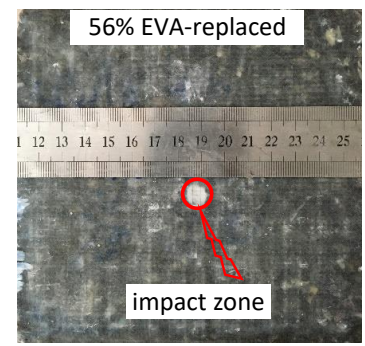

(F)

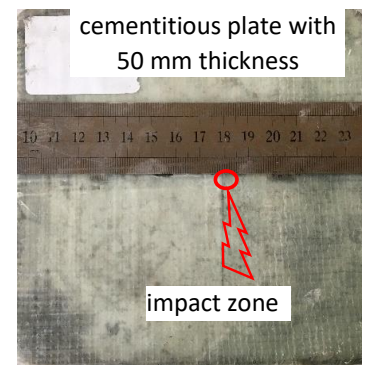

(I)

Fig. 8. Cementitious samples after impact test; (A) uncoated cementitious control plate (B) uncoated cementitious plate with EVA-replaced samples (C) coated sample 18\% EVA-replaced (D) coated sample 32\% EVAreplaced (E) coated sample 45\% EVA-replaced (F) coated sample 56\% EVA-replaced (G) coated control plate with $15 \mathrm{~mm}$ thickness $(\mathbf{H})$ coated control plate with $30 \mathrm{~mm}$ thickness (I) coated control plate with $50 \mathrm{~mm}$ thickness. EVA, ethylene vinyl acetate

cementitious plates, resultant to the effect of applied force. The level of stress decreased with the decrease of deformation; so, whitening formation tended to decrease with increasing sample thickness (Figure 8G-I). Since the thickness of the material increases, the bending strength increases [29].

\subsection{Theoretical formulations}

Peak impact force is an important parameter in structures subjected to impact load to evaluate the impact resistance behavior of the materi- als [30]. In this section, analytical models are used to approximately forecast the peak impact force of coated GFRP and uncoated GFRP-cementitious plates. Coated and uncoated plates are considered isotropic. In addition, friction and energy losses are neglected.

The mass-plate effect is modeled as an equivalent system, as shown in Figure 9 [30-32].

The initial velocity of the striker hitting the plate element is zero $(\mathrm{V}=0)$. The free-falling striker from the height $h_{0}$ suddenly hits the plate 


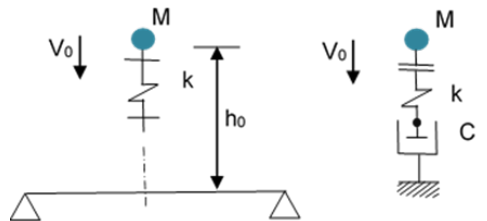

Fig. 9. Mass-plate impact sketch and equivalent system [30]

with velocity $V_{0}=\sqrt{2 g h_{0}}$. The impactor can be made simpler, as a spring (contact stiffness $k$ ), a vibration dampener $(C)$, and an impact mass $(M)$. The peak impact force, $P m$, is found according to Eqs (1)-(3) [30, 31].

$$
\begin{gathered}
P_{m} \approx\left(P_{m s}{ }^{-0.95}+P_{m d}{ }^{-0.95}\right)^{-1.053} \\
P_{m s}=V_{0} \sqrt{k M} \\
P_{m d}=C V_{0}
\end{gathered}
$$

where $P_{m s}$ is the value of peak contact force between the mass-spring system and the rigid plate and $P_{m d}$ is the peak damping force. The damper viscosity $(C)$ is shown in the following equation:

$$
C=2 \pi^{2} r_{0} \sqrt{G h_{s} m_{0} / 5}
$$

where $r_{0}$ is the radius of impact at the center of the plate under the effect of impact force, $r_{0}=h / 2$, and $\mathrm{h}$ is the plate thickness. $G$ is the shear modulus of the plate [30].

$$
G=\frac{E_{D}}{2\left(1+\mu_{c}\right)}
$$

where $E_{D}$ and $\mu_{c}$ are the modulus of elasticity and Poisson's ratio obtained by dynamic tests, respectively; $h_{s}$ is the shear thickness of a solid plate of thickness $h .\left(h_{s}=h / 1.2\right)$; and $m_{0}$ is the unit weight of the surface of the plate.

The contact stiffness $k$ in Eq. (2) is calculated with the help of Eq. (6), which is the impact model of the hard spherical impactor.

$$
k=2 \pi R f_{c}
$$

where $R$ is the distance from the point where the striker hits the sample to the support and $f_{c}$ is the dynamic bearing power.

Eqs (1)-(5) are used for the values in Method 1. The value of $k$ is calculated with the help of Eq. (6). Here, $f_{c}$, dynamic bearing power, is calculated by increasing the static compressive strength by $20 \%$.

The dynamic elasticity module is used in calculating the shear modulus. The following formulas are used for the dynamic elasticity calculation [33]:

$$
E_{S}=0.97 W^{2} \sqrt{U_{W}}
$$

$$
E_{D}=1.16 W^{2} \sqrt{U_{W}}
$$

$$
v=\frac{1}{E_{S}}\left[0.16 E_{S}+20 U_{W}\right]
$$

where $W\left(\mathrm{~kg} / \mathrm{m}^{3}\right)$ is the density of the concrete, $U_{W}$ $\left(\mathrm{N} / \mathrm{mm}^{2}\right)$ cubic compressive strength, $v$ Poisson ratio, and $E\left(\mathrm{kN} / \mathrm{mm}^{2}\right)$ concrete elasticity modules. Here, $s$ index represents static and $D$ index represents dynamic data.

Eqs (1)-(6) are used for the values in Method 2. The static elasticity modulus of the samples is calculated according to ACI 318-95 [34] using the stress values obtained from the pressure tests. The Poisson ratio is taken as $v=0.2$. While calculating the shear modulus, the dynamic elasticity module is used. The following formula is used for Method 2 of dynamic modulus of elasticity (GPa) [35].

$$
E_{S}=57000 \sqrt{f}(p s i)
$$

$$
E_{D}=\left(E_{S}+4.1\right) / 1.04
$$

In this theoretical calculation, the values encompassed in Method 1 are obtained by using the elasticity modules calculated with the help of the formulation defined for LWC. In Method 2, calculations are made with the help of known formulas (Eqs [1-6]) for standard concretes. 


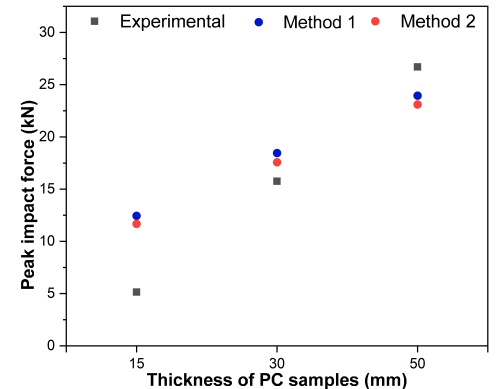

(A)

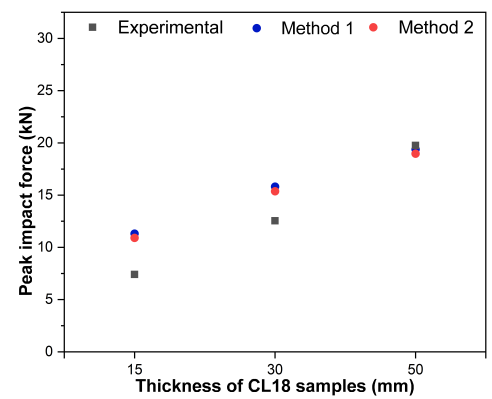

(D)

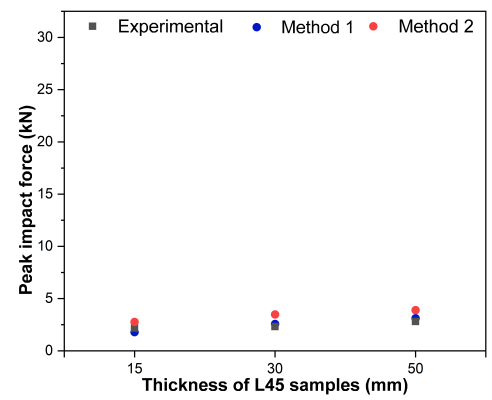

(G)

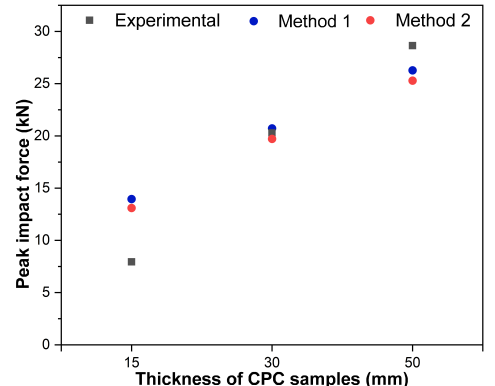

(B)

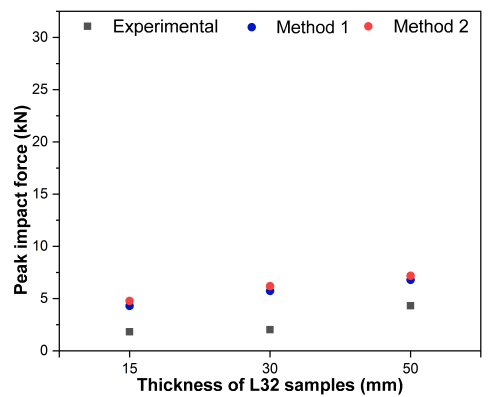

(E)

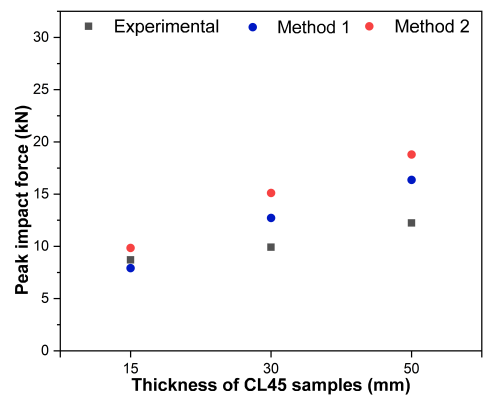

(H)

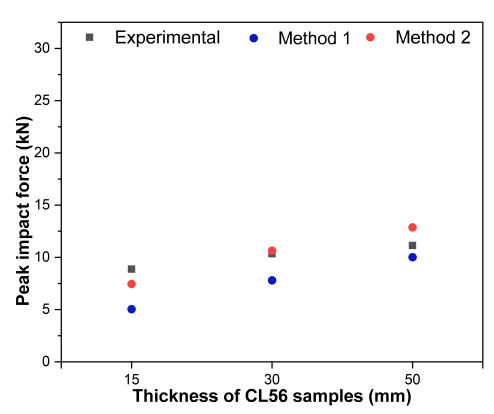

$(\mathrm{J})$

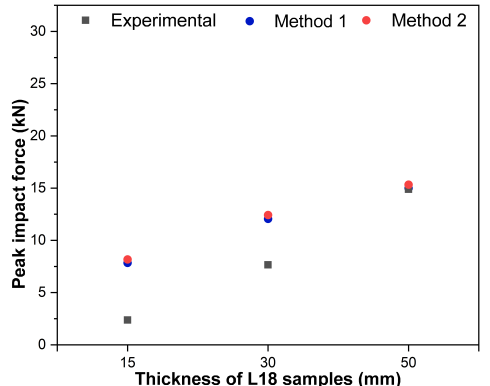

(C)

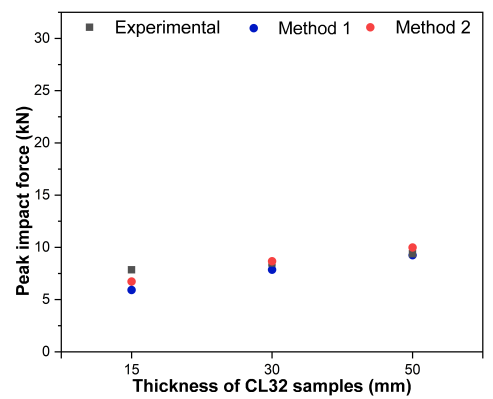

(F)

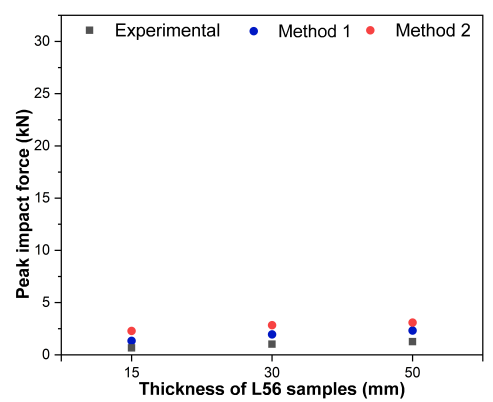

(I)

Fig. 10. Graphical representation of experimental and theoretical results for uncoated samples (A, C, E, G, I) and coated samples (B, D, F, H, J) 
The data including the comparison of the peak impact force values calculated with the help of Method 1 and Method 2 of the GFRP-coated and uncoated samples and the peak impact force values obtained from the experimental results are shown in Figure 10. When Figure 10 is examined, it is seen that the values obtained from the experimental studies and the theoretical data largely overlap with each other. When the cementitious samples are examined in detail, depending on the modification processes, the following conclusions can be reached.

When the peak impact force graphs of the coated and uncoated PC samples are examined (Figure 10A, B), it is seen that the data obtained based on Method 2 are closer to the experimental data. Considering the peak impact force graphs of the coated and uncoated samples with 18\% EVA replacement are examined (Figure 10C, D), it is determined that the peak impact force values obtained with Method 2 are closer than the experimental data, as in the samples without EVA replacement (Figure 10A, B). The reason for this is that the samples are in the normal weight concrete (NWC) class [29]. In cases where the EVA replacement rates are $32 \%$ (Figure 10E, F), 45\% (Figure 10G, H), and $56 \%$ (Figure 10I, J), the peak impact force values obtained from Method 1 are closer to the experimental values than those from Method 2. The reason for this is that the cementitious samples produced with the increasing EVA replacement rate fall into the LWC from the NWC class. This confirms the unit weight graphs shown in Figure 5.

When the Figure 10 are examined, the calculated peak impact force values are in good agreement with the experimentally obtained peak impact force values. However, there may be some difference between the calculated values and the experimental values, depending on the plate thickness, the amount of replacement EVA, and the amount of epoxy resin. It is apparent that the best agreement between experimental and theoretical results occurs with samples containing $32 \%$ EVA. Therefore, in EVA concrete, it is thought that concrete samples behave like EVA when the proportion of EVA exceeds $32 \%$. On examining the effect of the GFRP coating on the low-velocity impact behav- ior, it is ascertained that the GFRP coating process contributed to better agreement of the experimental results with the theoretical results in all samples without exception.

\section{Conclusion}

In this study, the experimental and theoretical behavior of cementitious plate containing waste EVA with and without reinforcement with GFRP under low-velocity impact load testing are investigated. The obtained results are briefly summarized below.

1. Using EVA, which is classified as hazardous waste by nature and requires large storage areas, instead of natural aggregate in cementitious structures, contributes to the protection of natural aggregate resources, while transforming waste EVA product into a useful product creates an alternative that reduces disposal costs and environmental pollution.

2. It is determined that since EVA has a lower density than natural aggregate, the unit weight values of cementitious samples decreased with the increase in the EVA replacement ratio. Specifically, cementitious samples that contained up to $32 \%$ EVA are in the NWC class, while samples containing $\geq 32 \%$ EVA are converted into LWC.

3. GFRP coating with vacuum infusion method is not recommended for cementitious plate structures when the EVA replacement rate exceeds $32 \%$ by volume of aggregate.

4. The peak impact force values of cementitious samples decrease as the EVA replacement ratio increases, while on the other hand, the peak impact force time is shifted to the right. This can be attributed to the fact that the EVA replacement increases the ductility of the samples.

5. While a single peak-pulse-peak is observed in GFRP uncoated samples, a double peakpulse-peak formation is observed in GFRP- 
coated samples. This is a result of the different impact strengths of the GFRP-added epoxy and cement core structure.

6. It is seen that the peak impact force values of the cementitious samples are compatible with the values obtained from the theoretical calculations and the experimental values. And this shows that by using the empirical equation obtained as a result of this study, it is predicted that the peak impact forces of GFRP-coated and uncoated cementitious plates with EVA replacement $(0 \%, 18 \%, 32 \%, 45 \%$ and $56 \%)$ can be calculated more economically and practically.

\section{References}

[1] Alfayez S, Ali MAEM, Nehdi ML. Eco-efficient fiberreinforced preplaced recycled aggregate concrete under impact loading, Infrastructures. 2019;4. https : //doi. org/10.3390/infrastructures 4020037 .

[2] Kennedy RP. A review of procedures for the analysis and design of concrete structures to resist missile impact effects, Nucl Eng Des. 1976;37:183-203. https : //doi .org/10.1016/0029-5493(76) 90015-7.

[3] Das Adhikary S, Li B, Fujikake K, Alhadid MMA, Soliman AM, Nehdi ML, et al. Critical overview of blast resistance of different concrete types. Mag Concr Res. 2014;66:72-81. https://doi.org/10. $1680 /$ macr . 13.00096.

[4] Yoo D-Y, Banthia N. Impact resistance of fiberreinforced concrete - A review. Cem Concr Compos. 2019;104:103389. https://doi.org/10.1016/ j. cemconcomp. 2019. 103389.

[5] Vadivel TS, Thenmozhi R, Doddurani M. Experimental behaviour of waste tyre rubber aggregate concrete under impact loading. Iran J Sci Technol Trans Civ Eng. 2014;38:251-9.

[6] Alwesabi EAH, Bakar BHA, Alshaikh IMH, Zeyad AM, Altheeb A, Alghamdi H. Experimental investigation on fracture characteristics of plain and rubberized concrete containing hybrid steel-polypropylene fiber. Structures. 2021;33:4421-32. https://doi.org/10. $1016 / \mathrm{j}$. istruc . 2021.07.011.

[7] Ismail ZZ, AL-Hashmi EA. Use of waste plastic in concrete mixture as aggregate replacement. Waste Manag. 2008;28:2041-7. https://doi.org/ 10.1016/j . wasman.2007.08.023.

[8] Makul N, Fediuk R, Amran M, Zeyad AM, de Azevedo ARG, Klyuev S, et al. Capacity to develop recycled aggregate concrete in South East Asia. Buildings. 2021;11:234. https://doi .org/10. 3390/buildings11060234.

[9] Makul N, Fediuk R, Amran M, Zeyad AM, Murali G, Vatin $\mathrm{N}$, et al. Vasilev, use of recycled concrete ag- gregates in production of green cement-based concrete composites: A review. Crystals. 2021;11:232. https : //doi .org/10.3390/cryst11030232.

[10] Marcilla A, Gómez A, Menargues S. TG/FTIR study of the thermal pyrolysis of EVA copolymers. J Anal Appl Pyrolysis. 2005;74:224-30. https://doi.org/ 10.1016/J J JAAP . 2004.09.009.

[11] Uçar S, Ozkan AR, Yanik J, Karagöz S. The influence of the waste ethylene vinyl acetate copolymer on the thermal degradation of the waste polypropylene. Fuel Process Technol. 2008;89:1201-6. https : //doi .org/ 10.1016/J .FUPROC. 2008.05.010.

[12] Lopes D, Ferreira MJ, Russo R, Dias JM. Natural and synthetic rubber/waste - Ethylene-vinyl acetate composites for sustainable application in the footwear industry. J Clean Prod. 2015;92:230-6. https://doi .org/10 . 1016/j.jclepro.2014.12.063.

[13] Rimez B, Rahier H, Van Assche G, Artoos T, Biesemans M, Van Mele B. The thermal degradation of poly(vinyl acetate) and poly(ethylene-co-vinyl acetate), Part I: Experimental study of the degradation mechanism. Polym Degrad Stab. 2008;93:800-10. https://doi .org/10. 1016/J . POLYMDEGRADST AB . 2008.01.010.

[14] Lima PRL, Leite MB, Santiago EQR. Recycled lightweight concrete made from footwear industry waste and CDW. Waste Manag. 2010;30:1107-13. https: // doi .org/10.1016/J .WASMAN . 2010.02.007.

[15] Zuchetto L, Oliveira MF, Tutikian B. Dynamic stiffness evaluation of floor covering system made out of recycled EVA - Ethylene vinyl acetate. In: INTER-NOISE 2015, 44th International Congress and Exposition on Noise Control Engineering. San francisko, California; 2015.

[16] Magbool HM, Zeyad AM. The effect of various steel fibers and volcanic pumice powder on fracture characteristics of self-compacting concrete. Constr Build Mater. 2021;312:125444. https : //doi .org/ 10.1016/ j. conbuildmat. 2021.125444.

[17] Balcikanli Bankir M, Sevim UK. Performance optimization of hybrid fiber concrete according to mechanical properties. Constr Build Mater. 2020;261:119952. https ://doi .org/10.1016/J. CONBUILDMAT . 2020.119952.

[18] Anil Ö, Kantar E, Yilmaz MC. Low velocity impact behavior of RC slabs with different support types. Constr Build Mater. 2015;93:1078-88. https : //doi .org/ 10.1016/ J . CONBUILDMA T . 2015.05.039.

[19] Mubin SM, Syamsir A, Mohamad D. A review on experimental and numerical studies of Glass Fibre Reinforced Polymer (GFRP) strips strengthened Reinforced Concrete (RC) slab subjected to low velocity impact. In: 2nd International Conference on Disaster Management. IOP Publishing; 2021. https://doi.org/10. 1088/1755-1315/708/1/012075.

[20] Strong AB. Fundamentals of composites manufacturing - materials, methods, and applications, 2nd, Society of Manufacturing Engineers (SME); 2008.

[21] Chawla KK. Composite materials, 4th, Springer Na- 
ture Switzerland; 2019. https://doi.org/10.1007/ 978-3-030-28983-6.

[22] Balasubramanian M. Composite materials and processing. 1st ed. CRC Press; 2013.

[23] TS EN 998-2, Specification for mortar for masonry - Part 2: Masonry Mortar, Ankara; 2017.

[24] ASTM C349-02. Standard test method for compressive strength of hydraulic-cement mortars (using portions of prisms broken in flexure). West Conshohocken, PA, www.astm.org; 2002. https://doi.org/10.1520/ C0349-02.

[25] Yang X, Liu J, Li H, Ren Q. Performance and ITZ of pervious concrete modified by vinyl acetate and ethylene copolymer dispersible powder. Constr Build Mater. 2020;235:117532. https://doi.org/ 10.1016/J . CONBUILDMAT . 2019.117532.

[26] Dong Z, Wu G,. Zhao XL, Zhu H, Wei Y, Yan Z. Mechanical properties of discrete BFRP needles reinforced seawater sea-sand concrete-filled GFRP tubular stub columns. Constr Build Mater. 2020;244:118330. https://doi.org/10.1016/J.CONBUILDMA T . 2020.118330 .

[27] Huang L, Sun X, Yan L, Kasal B. Impact behavior of concrete columns confined by both GFRP tube and steel spiral reinforcement. Constr Build Mater. 2017;131:438-448. https://doi.org/10.1016/J. CONBUILDMAT . 2016.11.095.

[28] Cheng S, Feng P, Li Z, Du J. Mechanical behavior of cylindrical GFRP chimney liners subjected to axial tension. Compos Part B Eng. 2019;177:107411. https : // doi . org/10.1016/J . COMPOSITESB . 2019. 107411.
[29] Alhassan EA, Olasehinde DA, Musonda A, Odeniyi OM. Tensile and flexural behaviour of steel materials used in the construction of crop processing machines. In: IOP Conference Sereies Earth and Environmental Science. IOP Publishing, Kwara State; 2020. https : / / doi.org/doi : 10.1088/1755-1315/445/1/012044.

[30] Wang W, Chouw N. Experimental and theoretical studies of flax FRP strengthened coconut fibre reinforced concrete slabs under impact loadings. Constr Build Mater. 2018;171:546-557. https ://doi.org/ 10.1016/ j.conbuildmat.2018.03.149.

[31] Szuladzinski G. Formulas for mechanical and structural shock and impact. CRC Press/Taylor \& Francis Group; 2010.

[32] Szuladzinski G. Mass-plate impact parameters for the elastic range. Acta Mech. 2008;200:111-125. https : //doi .org/10.1007/s00707-008-0578-5.

[33] Swamy RN. The elastic properties of structural lightweight concrete. Proc Inst Civ Eng. 1975;2:381394.

[34] A.C. 318. Building code requirements for structural concrete (ACI 318-95) and commentary (ACI 318R-95); 1995.

[35] Jin-Keun K, Hoon K, Jae-Ho N. Estimation of mechanical properties of concrete in early age by resonance frequency test. Mag Korea Concr Inst. 1995;7:164-171. https://doi .org/10.22636/MKCI . 1995.7.5.164.

Received 2021-10-25 Accepted 2022-01-19 